\title{
Mechanism for Resistance Reduction of Spoilers under the changes of Floating Condition based on Fluent
}

\author{
Huang $\mathrm{Ji}^{1, \mathrm{a}}$, Wang Tianlin ${ }^{2, \mathrm{~b}}$, Liu Chao ${ }^{2, \mathrm{c}}$, Yun Yajie ${ }^{3, \mathrm{~d}}$ \\ ( 1.Guangdong Ocean University, College of Engineering, 524000 )
}

(2. Dalian Maritime University, Institute of transportation equipment and Marine engineering, 116026 )

\author{
( 3.Qingdao Ocean Shipping Mariners College, The ship sea system, 266000) \\ aemail: huangji@163.com, \\ bemail:wangtl@163.com, cemail:dmuhy@126.com, demail:yunyj@126.com
}

Keywords: Spoilers; Floating condition; Ship; Resistance; Trim angle

\begin{abstract}
The effect of the spoilers depend considerably on the lift and trim moment that change the floating condition of the ship and then influence the flow field near the stern and the resistance of the ship. To investigate the effect of the spoilers on on the ship resistance caused by lift and trim moment separately, a speed square tail boat is introduced to this study as the object to discuss the changes of the resistance with and without the consideration of floating consideration. Furthermore, the resistance variations of the ship using the spoilers with the variation of the trim angle are compared with the ones without the spoiler in numerical analysis.
\end{abstract}

\section{Introduction}

Recently, the spoiler has been applied into the small and medium sized vessels to improve ships' dynamic performance at high speeds as a appendage [1-2]. The shape of the spoiler is similar with the vertical tailgate. The experiments from F. Stern et al.[3] show that the resistances were reduced by installing spoilers and it's more convenient to install and adjust the wave-controlled tail plate and wedge tail plate. The spoilers are classified into a constant-height fixed type and a changeable-height adjustable. The the spoilers are equipped using continuous or discontinuous method along the transverse direction of the ship, with the ship beam in width and one thousandth of the ship length in height. Therefore, the load condition and the trim of the ship are influenced greatly[4] by the arrangement of the spoilers

Study on mechanisms for resistance reduction of the spoiler have been investigated numerously by the a lot of researchers. For small and medium sized high speed ship with the spoilers, wave resistance is reduced by improving wake at aft and increase the virtual length of the tail, and viscous pressure resistance and reduce friction resistance are decreased due to the increase of the lift and the moment of trim by head. Furthermore propulsion performance and navigation state are also improved and improve [5-7].

However, the resistance reduction just induced by the lift and trim moment has not yet been investigated clearly. . Therefore, in the paper a simplified two-dimensional ship model was firstly built to analyze the variations of total resistance, lift and trim moment with calculation conditions including the spoiler, height, the speed and daft of the ship based on the viscous theory using Fluent. Secondly, a three-dimensional model of the high-speed square tail ship with and without a spoiler was simulated numerically under the same condition as that in two-dimensional model. In addition, the modifications of the floating condition on the variation of the lift and trim moment were carried out to compare the resistance between consideration and non-consideration of the floating condition change. Finally, compared the simulation results from the three-dimension model without the spoiler, the effect of trim moment on resistance reduction was analyzed. the trim angle without spoilers and analyze the impact of ship resistance varies the trim moment with spoilers .

\section{Analysis on the mechanism for resistance reduction using two-dimensional model}

A two-dimensional model of flat-bottom hull was developed into numerical simulation to investigate the mechanism for resistance reduction of the spoiler. It was assumed that the velocity attenuation of the 
fluid caused by the transverse motion of the ship and the influence of interference between $t$ the spoilers and the hull caused by the difference of the ship-lines. The calculation model shown in Fig. 1 was simulated under the different calculation condition with respects to the height of spoiler, the speed and the draft of the ship.

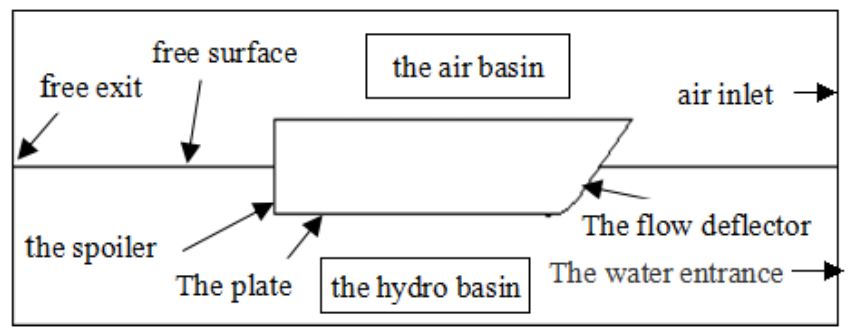

Fig. 1 Model for Watershed Scale

The table 1 shows the simulation results in the cases of the spoilers in height of $0 \mathrm{~mm}, 4 \mathrm{~mm}, 40 \mathrm{~mm}$, $400 \mathrm{~mm}$ at the speed of $4.88 \mathrm{~m} / \mathrm{s}$, the draft of $0.25 \mathrm{~m}$, respectively. The calculation conditions of the spoiler height respect ,1/1000, 1/100, 1/10 of the ship length and no spoilers, respectively.

Tab 1. Simulation results under the different height of spoilers

\begin{tabular}{cccccc}
\hline $\mathrm{H}$ & $\mathrm{PR}$ & $\mathrm{SR}$ & $\mathrm{TR}$ & $\mathrm{PL}$ & $\mathrm{TRPL}$ \\
$/ \mathrm{mm}$ & $/ \mathrm{KN}$ & $/ \mathrm{KN}$ & $/ \mathrm{KN}$ & $/ \mathrm{KN}$ & $\%$ \\
\hline 0 & 129.0 & 0 & 129.0 & 4671.5 & 2.8 \\
4 & 125.5 & 27.0 & 152.5 & 5986.4 & 2.5 \\
40 & 113.8 & 392.8 & 506.5 & 11930.5 & 4.2 \\
400 & 80.1 & 7074.5 & 7154.5 & 37271.9 & 19.2 \\
\hline
\end{tabular}

Note: H is short for height; PR is short for plate resistance; SR is short for spoilers resistance; TR is short for total resistance; PL is short for plate lift; TRPL is short for total resistance plate lift .

From the 1, it was found that the height of the spoilers influenced considerably on the total resistance and the lift for two-dimensional ship model. The total resistance increases sharply with the increase of the spoiler height while plate resistance of spoilers decreases. According to the variation of the ratio of the total resistance to the lift with the height of the spoiler, the minimum values about the ratio was suggested to be found under the condition of the spoiler height from between $4 \mathrm{~mm}$ and $40 \mathrm{~mm}$ of the spoiler height (1/100 to $1 / 1000$ of the ship length).

Tab 2. Different velocity of the spoilers

\begin{tabular}{|c|c|c|c|c|c|}
\hline $\begin{array}{c}\mathrm{V} \\
/ \mathrm{Kn} \\
\end{array}$ & $\begin{array}{c}\mathrm{PR} \\
/ \mathrm{KN}\end{array}$ & $\begin{array}{c}\mathrm{SR} \\
/ \mathrm{KN} \\
\end{array}$ & $\begin{array}{c}\text { TR } \\
/ \mathrm{KN}\end{array}$ & $\begin{array}{c}\mathrm{PL} \\
/ \mathrm{KN}\end{array}$ & $\begin{array}{c}\text { TRPL } \\
\% \\
\end{array}$ \\
\hline 20 & 66.4 & 15.3 & 81.7 & 6844.8 & 1.2 \\
\hline 30 & 125.5 & 28.6 & 154.1 & 5986.4 & 2.5 \\
\hline 40 & 193.3 & 43.2 & 236.5 & 4435.5 & 5.3 \\
\hline 50 & 278.9 & 62.3 & 341.3 & 2748.1 & 12.4 \\
\hline 60 & 372.9 & 81.3 & 454.2 & 1135.1 & 40.0 \\
\hline
\end{tabular}

The table 2 shows the simulation results in the cases of the ship speed of $3.25 \mathrm{~m} / \mathrm{s} 、 4.88 \mathrm{~m} / \mathrm{s}$ 、 $6.50 \mathrm{~m} / \mathrm{s} 、 8.13 \mathrm{~m} / \mathrm{s} 、 9.75 \mathrm{~m} / \mathrm{s}$ when the height of the spoilers is $4 \mathrm{~mm}$ and the draft is $0.25 \mathrm{~m}$, respectively.

In table 2, the plate resistance and the spoiler resistance increased with the increase of the ship speed. The reason can be that the stress upon the bottom of the ship become small induced by the quick reparation of the water with large kinetic energy from the bottom of the ship quickly. the plate lift And decreased gradually as the speed was increasing induced by the decrease of the lift. Additionally, the proportion of the spoiler resistance in total resistance reduce. The obstruction effect of the spoilers was considered to be small at relatively high speed for the two-dimensional ship. and meanwhile the ratio of resistance and the lift increases caused by the speed increasing, for velocity increases and resistance increases while the lift decreases.

In table 3, describes simulation results in the cases of the draft of $0.25 \mathrm{~m}$ (regular draft), 0.225 (1/10 reduction on the draft) $8,0.2 \mathrm{~m}$ ( $2 / 10$ reduction on the draft), $0.175 \mathrm{~m}$ ( $3 / 10$ reduction on the draft) , when the height of the spoilers is $4 \mathrm{~mm}$ and the speed is $4.88 \mathrm{~m} / \mathrm{s}$, respectively. 
Tab 3. Different draft of the spoilers

\begin{tabular}{ccccc}
\hline $\mathrm{D}$ & $\mathrm{PR}$ & $\mathrm{SR}$ & $\mathrm{TR}$ & $\mathrm{PL}$ \\
$/ \mathrm{mm}$ & $/ \mathrm{KN}$ & $/ \mathrm{KN}$ & $/ \mathrm{KN}$ & $/ \mathrm{KN}$ \\
\hline 250 & 125.47 & 26.98 & 152.45 & 5986.38 \\
225 & 123.83 & 26.34 & 150.17 & 5473.34 \\
200 & 123.68 & 25.93 & 149.62 & 5151.22 \\
175 & 123.17 & 25.49 & 148.66 & 4734.19 \\
\hline
\end{tabular}

Note: $\mathrm{D}$ is short for draft

From the table 3 the plate resistance, the spoiler resistance and the lift decreased with the reduction of the draft. In the two-dimensional model, the wetted surface area is only related to the length of the plate and the height of the spoilers. Although the draft varies, the the wetted surface area was not changed. Therefore, it is concluded that the decrease of the draft changed the flowing field under the ship so that the viscous pressure resistance decreased. And the plate lift decreased with draft decreasing.

Based on results mentioned above in two-dimensional model with the spoilers, it was found that the viscous pressure resistance was reduced due to rising the ship and reduce the increase of the lift. Furthermore a trim by head moment generated by and the increase of the lift and the resistance of the spoiler can counteract the trim by stern of the ship at high speed and so as to improve the navigation as well as reduce the resistance.

\section{Analysis on the mechanism for resistance reduction using three-dimensional model}

Based on the two-dimensional ship model, a three-dimensional model was built to analyze the mechanism for resistance reduction deeply. The calculation model was set to be a high-speed square tail vessel with $49.7 \mathrm{~m}$ in length, $9.10 \mathrm{~m}$ in breadth. Additionally, the spoiler length is $4 \mathrm{~m}$ and the draft is $0.25 \mathrm{~m}$. table 4 shows numerical analysis on the total resistance, the lift and total trimming moment with and without a $20 \mathrm{~mm}$ high spoiler at the speed of $20 \mathrm{kn}, 30 \mathrm{kn}, 40 \mathrm{kn}, 50 \mathrm{kn}, 60 \mathrm{kn}$, respectively.

In table 4, the total resistance of the ship with a spoiler was less than that with no spoiler at the speed of $40 \mathrm{kn}$. it proved that the spoiler has a positive effect on the ship resistance reduction; the flow separation became dramatic and the life decreases and the trim moment increased with the rise of speed.

Tab. 4 The total resistance with a spoiler compare with no spoiler at the different velocity

\begin{tabular}{ccccccc}
\hline \multirow{2}{*}{$\begin{array}{c}\text { V } \\
\text { /kn }\end{array}$} & \multicolumn{2}{c}{$\begin{array}{c}\text { HTR } \\
\text { /KN }\end{array}$} & \multicolumn{2}{c}{ TLF } & \multicolumn{2}{c}{ TTM } \\
& NS & S & NS & S & NS & S \\
\hline 20 & 288.0 & 311.9 & 5265.0 & 5317.7 & 7922.9 & 7080.5 \\
30 & 520.6 & 522.8 & 4975.2 & 5114.5 & 9785.5 & 7556.6 \\
40 & 839.2 & 826.9 & 4559.1 & 4768.8 & 11383.1 & 8027.6 \\
50 & 1248.6 & 1262.8 & 4044.9 & 4328.0 & 13083.2 & 8552.9 \\
60 & 1737.2 & 1773.5 & 3349.9 & 3684.9 & 14987.9 & 9628.1 \\
\hline
\end{tabular}

Note: HTR is short for hull total resistance; TLF is short for total lift force; TTM is short for total trimming moment; NS is short for no spoiler; $\mathrm{S}$ is short for spoiler .

When the ship is navigating on the sea , fluid flows around the ship leads to the pressure change of bottom and thus causes an unbalanced load on ship, so as to produce the ship heave and the change of the trim, the vertical load and total moment on the ship. Based on the analysis on resistance reduction in the 2D model, the main role of the spoiler is to increase flat lift and generate the trim by head moment. Consequently, it is necessary to consider the effect of the ship heave and trim on the ship resistance.

Assuming that the rotation center of gravity was the center of gravity to a ship, the procedures of modifications of the ship heave and the trim are as follows :

a. Divide the ship into a number of zones, and then perform an upright condition of the ship using FLUENT. the force in different area of the ship surface, and the relative moment to the center of gravity were recorded until the results of the calculations were converged.

b. According to the results in (a),the force and the moment of a ship were calculated under upright condition, and then the heave and trim were worked out to balance the force and the moment of the ship. 
c. the grid division was carried out again and repeat the steps (a) and (b)until difference of calculated results was small, and then the modification was finished.

Considering that the size of the spoiler was further smaller than the ship, it's difficult to divide the grid. Therefore we just made the modification on the heave in terms of the lift force.

Through the numerical simulation under upright condition, it can be obtained that the life of the ship with and without the spoiler are presented to be $f_{s}$ and $f_{s}$, respectively. Then we can calculate $\Delta f=f_{s}-f_{s}$, using HYDROMAX to under the different displacements and the different drafts, respectively. Next, $\Delta f$ was used to build an equation and to obtain the correct waterline position.

From the simulation results in 4 , it is found that the effect of spoiler was not too obvious at low speed, and the change of the ratio of the lift to the total resistance was small although the height of the spoiler was changed; at high speed, the ratio of the ship with the spoiler was smaller than that without the spoiler.Next,HYDROMAX was applied to modifying floating conditions to get the new floating condition as shown in table5.

Tab 5. floating state correction data table

\begin{tabular}{ccc}
\hline $\begin{array}{c}\text { Speed } \\
/ \mathrm{Kn}\end{array}$ & $\begin{array}{c}\text { Life force difference } \\
/ \mathrm{KN}\end{array}$ & $\begin{array}{c}\text { Draft } \\
/ \mathrm{m}\end{array}$ \\
\hline 20 & 52.65 & 2.540 \\
30 & 139.31 & 2.515 \\
40 & 209.72 & 2.495 \\
50 & 283.14 & 2.475 \\
60 & 334.99 & 2.465 \\
\hline
\end{tabular}

Form table 5, the lift raised with the speed increase change increasinglythe ship lift height. The data in 5 were introduced into the simulation to get the new results about the resistance shown as follows:

Tab 6. Lifting force after correction resistance table

\begin{tabular}{cccccc}
\hline $\mathrm{V}$ & $\mathrm{Ns}$ & $\mathrm{S}$ & $\mathrm{LFC}$ & $\mathrm{RD} 1$ & $\mathrm{RD} 2$ \\
$/ \mathrm{Kn}$ & $/ \mathrm{KN}$ & $/ \mathrm{KN}$ & $/ \mathrm{KN}$ & $/ \%$ & 7.74 \\
\hline 20 & 287.98 & 311.88 & 310.27 & 8.30 & -1.56 \\
30 & 520.64 & 522.82 & 512.54 & 0.42 & -2.50 \\
40 & 839.19 & 826.95 & 818.24 & -1.46 & -1.40 \\
50 & 1248.63 & 1262.72 & 1231.09 & 1.13 & -1.10 \\
60 & 1737.21 & 1773.53 & 1718.11 & 2.09 & \\
\hline
\end{tabular}

Note: LFC is short for lift force corrected; RD is short for relative difference.

As shown in the table 6, the viscous pressure resistance was reduced due to the decrease of the wetted surface area and draft and the resistances of the ship with a $20 \mathrm{~mm}$ high spoiler became small after the modification of the lift.At the $20 \mathrm{kn}$ speed, the change of the resistance is small because the lifting height of the ship after modified is small while the change of the resistance is great at the $60 \mathrm{kn}$ speed. The modified total resistance decreased $3.19 \%$ of that on the normal navigation with a $20 \mathrm{~mm}$ high spoiler. Furthermore, it was found that the resistance reduction of the ship with the spoiler can reach to $2.50 \%$ compared to the ship without the spoilers after the lifting force has been corrected.

From a comparison between 4 and 6 , , the rate and the speed range of the resistance reduction in 4 increased with the spoiler. Therefore, it is necessary to consider the effect of the lift change on the resistance reduction of the ship with the spoiler.

As shown in 4, the trimming by the stern was intensified with the increasing of speed. Furthermore, the trimming by the stern was attenuated due to the increase of the head trim moment produced by the spoiler.

Figure 2 shows that the numerical simulation about changes of angle of trimming of the ship without spoiler at the velocity of $40 \mathrm{kn}$. 


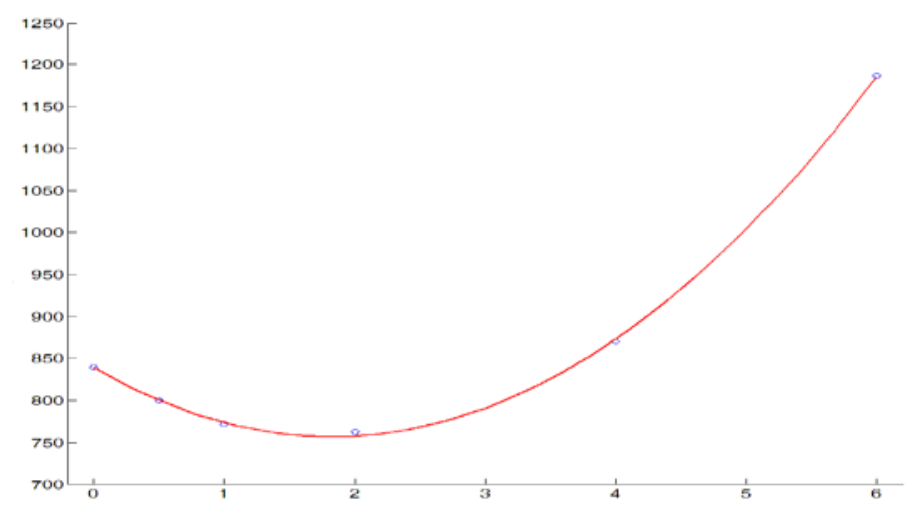

Fig 2. Without spoilers hull trim Angle change resistance

From the Fig. 2, the resistance of ship varied with of angle of trimming in the ship. In a certain range, the resistance of the ship decreases with the increasing of angle of trimming. It agrees with the fact that appropriate trimming by stern could reduce the resistance of the high-speed ships. However, the resistance of the ship increases dramatically when angle of trimming is beyond the critical value. Therefore, it is concluded that the trimming by stern play a positive role on resistance reduction of the ships to some extent, but if the trimming by stern is over-sized, it would lead to the increase of the resistance and decrease the working efficiency of the propeller so as to make seaworthiness worse.

The trimming by the stern is produced inevitably on navigation for the high-speed ships, and heightens s dramatically with the increase of the speed. The stern trimming of the ship can be offset by the head trimming produced by the spoiler. The spoiler makes contributions to the resistance reduction of the ship in the case of high speed.

\section{Conclusion}

In this paper, the conclusions based on the research of the lifting force and moment to trim were shown as follows:

1) The lift was increased by the spoiler of the ship, and the rate of resistance-reduction reach to $2.50 \%$ after the modifications of the floating condition. Furthermore, the velocity range of the resistance reduction also was changed accordingly. Therefore, it's necessary to consider the change of the flotation condition in order to study the mechanism for resistance reduction of the spoiler.

2) Ship resistance was closely related to the angle of trimming; the ship resistance was increased exponentially by the excessive trimming by the stern. A big moment of head trimming induced by the ship spoiler decreased the trimming by the stern. In a certain range, the spoiler played a positive role on the resistance reduction of the ship.

In the paper, some assumptions on the modification of the floating conditions were made to investigate the mechanism for the resistance reduction of the spoiler. On the other hand, the numerical simulations were not carried out for the ship with the spoiler in the case of trimming moment due to the restriction of computers, operation ability. These reasons induced the slight difference of the resistance reduction between the numerical analysis and the real results. In the future, the changes of the heaving and trimming of the ship are necessary to be considered to improve the precision of calculation.

\section{References}

[1] Wang Wen-jiang, Zong Zhi. Model Tests of Effects of Interceptor on Resistance of a Semi-Planing Ship[J]. Chinese Journal of Ship Research, 2012.2: 18-22.

[2] F. Stern, J. Huang, P, Carrica, J. Yang, S. Ghosh, S. Van. Two-Phase CFD and PIV EFD for Plunging Breaking Waves, Including Alternative CFD Approaches and Extensions for Air/Water Vessel Flow[C]. 26th Symposium on Naval Hydrodynamics,2006.

[3] Ji Heng-teng, Chen Jia-rong, Li Wei. Several Stern Modification Measures for Warships[J]. Chinese Journal of Ship Research, 2006, 1(3): 41-46. 
[4] Deng rui, Numerical research on Influence of the Interceptor on catamaran hydrodynamic performances[D], Harbin, Harbin Engineering University, 2010

[5] DAYAH, COOPER C. An experimental study of interceptors for drag reduction on high—performance sailing yachts[J].Ocean Engineering, 2011, 38(8/9): 983-994.

[6] MA Jian, ZHANG Zai-fu, LI Hui-min. Influencing factors of residual resistance and a prediction method of total resistance about wave-piercing catamaran[J]. Journal of Ship Mechanics, 2011. 2: 32-39.

[7] Deng Rui, Huang Debo, Numerical research on hydrodynamic performance of catamarans with interceptors[J]. J.Huazhong Univ. Of sci. \& Tech (Natural science Edition), 2011. 4: 97-100 